
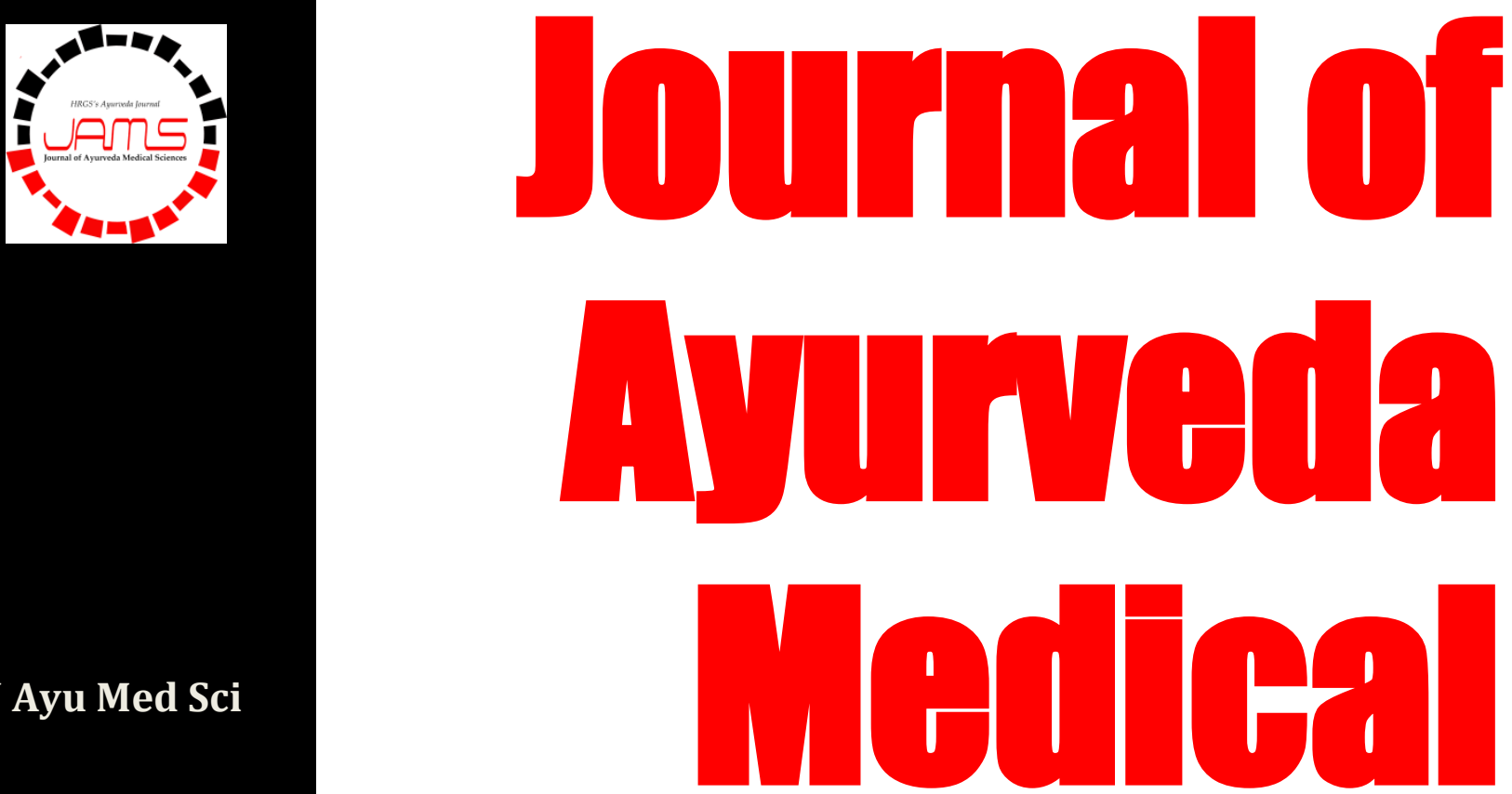

Quarterly Journal for

Rapid Publication

of Researches

in Ayurveda

and Other Traditional

Medicines

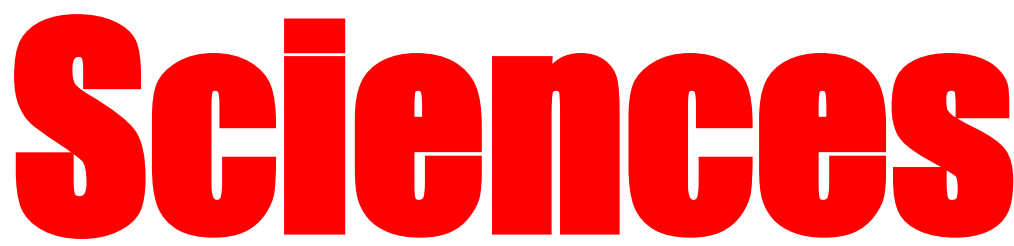

www.jayumedsci.com

ISSN 2456-4990

\title{
Pharmacognostic evaluation of ingredient drug of Valampuritailam: Helicteres isora L. fruit
}

Siddha system of medicine was practiced thousands of years back. According to Siddha maruthuvar almost all plants bear medicinal properties. The medicinal properties are due to the phytochemicals found in them. Due to abundant availability these plants were used without any particular standardization process and safety precautions in the past. Nowadays due to declined herbal population and adulteration of the available species with plants devoid of concerned medicinal potential, authentication from eminent botanist is inevitable. The macro-microscopic approach of Pharmacognosy helps in resolving these authentication issues.

Andalil et al. 


\section{Pharmacognostic Evaluation of Key Ingredient of Valampuritalam: He/icteres ísora L. fruit}

Remya Andalil, Rubeena Mattummal, Divya Kallingilkalathil Gopi, Brindha Sundaramoorthy, Erni Bobbili, Sunil Kumar Koppala Narayana*

Department of Pharmacognosy, Siddha Central Research Institute (Central Council for Research in Siddha, Ministry of AYUSH, Govt. of India), Arumbakkam, Chennai 600106, India.

\section{ABSTRACT}

Introduction: Helicteres isora L. is commonly known as Indian screw tree is described in indigenous medicinal systems as an important medicinal plant. It is a rich source of nutrients and antioxidants having high therapeutic values. Different parts of plant are used in various traditional systems for treating various ailments. Due to the healing property of fruits it is being exploited in the preparation of Siddha formulation Valampuritailam. Method: The fruit samples were collected from Siddha Medicinal Plant Garden, Mettur and pharmacognostic studies like macro-microscopic studies, powder microscopy, etc. were carried out to evaluate the drug for authentication. The twisted appearance of fruit is characteristic feature of plant. The microscopic study showed presence of three distinct layers in the fruit namely epicarp, mesocarp and endocarp. The powder showed characters like stellate trichomes, prismatic crystals and endosperm cells. Discussion: The plant is confused in the ayurvedic descriptions with that of Marsdinea tenassicima W. \& A. and leaves show similarity with Grevia asiatica Linn. But the fruits can be easily distinguished as it is having twisted appearance. The twists look like intestine which indicates its use in abdominal disorders. Conclusion: The present study aims the pharmacognostical characterization of fruit of $H$. isorato fulfill the authentication of the drug.

KEYWORDS Valampuri, Indian screw tree, Powder microscopy, Siddha formulation, Stellate trichomes.

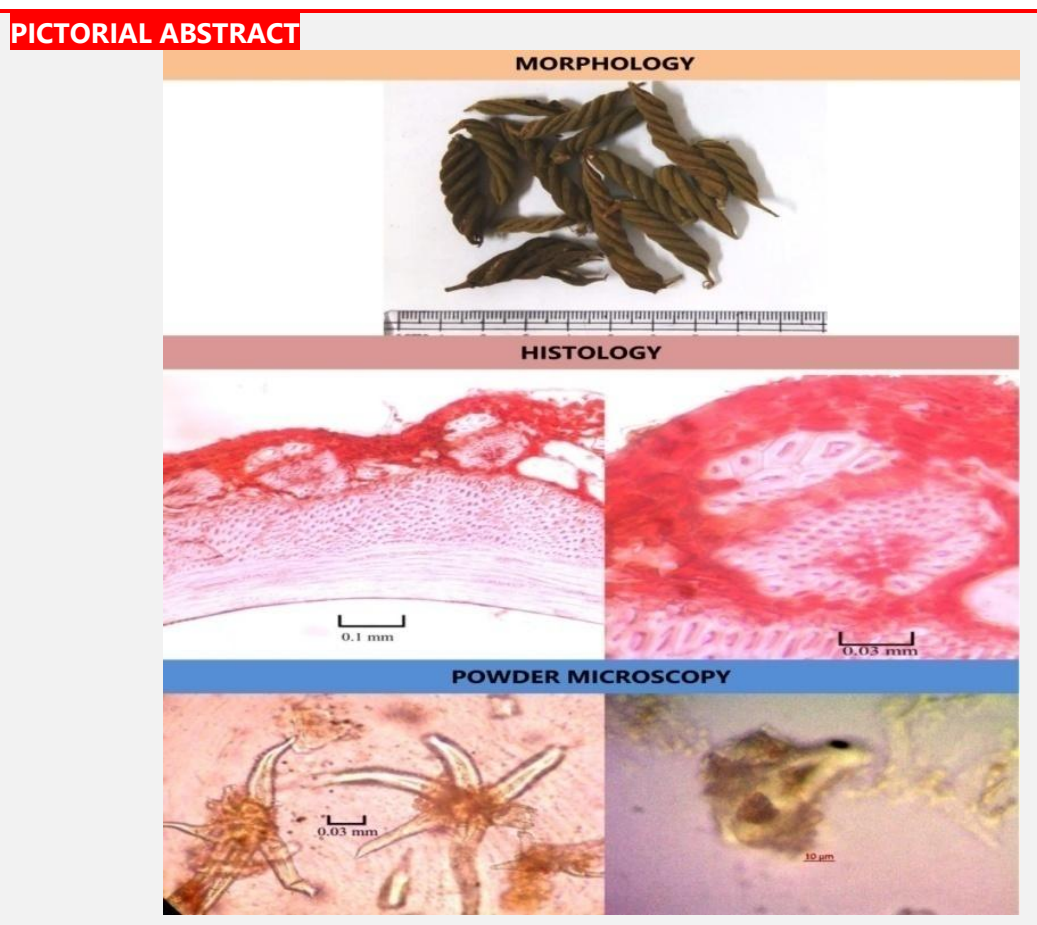

ARTICLE HISTORY Received 19.01.2019 Accepted 18.07.2019

CORRESPONDENCE Dr KN Sunil Kumar, Research Officer (Pharmacognosy), Siddha Central Research Institute, CCRS, Ministry of AYUSH, Anna Hospital Campus, Arumbakkam, Chennai 600106, India. Email: kn.sunil@gov.in

CITE THIS RESEARCH AS Andalil R, Mattummal R, Gopi DK, Sundaramoorthy B, Bobbili E, Narayana SKK. Pharmacognostic Evaluation of Key Ingredient of Valampuritailam: Helicteres isora L. fruit. J Ayu Med Sci 2018;3(4):446-50.

DOI 10.5530/jams.2018.3.27
Helicteres isora L. is one of the members of family Sterculiaceae, known as valampuri in Siddha literature. It is a small tree or shrub; young branches have dispersed stellate hairs with serrated leaves showing rough upper surface and pubescent inner surface. The young flowers are red and converted to blue when become old and are arranged solitary or in sparse cluster. Spirally twisted 5 carpelled fruits are the important feature of the plant with tuberculated seeds. ${ }^{[1]}$ It flowers during April to December and the fruiting season is October to June. ${ }^{[2]}$ It is distributed all over India above $1500 \mathrm{~m}$ of sea level and dry deciduous forests. ${ }^{[3]}$ In siddha system of medicine, it is used to make Valampuritailam for all head related diseases. ${ }^{[4]}$ The tribals in Bihar, uses the fruit as amulet in neck to treat malnutrition (locally known as dubli) diseases in children. ${ }^{[5]}$ Because of the antioxidant and anti-bacterial activity ${ }^{[6]}$, it is important medicinally and shows hypolipidemic, antibacterial, antiplasmid, cardiac antioxidant, antiperoxidative potency, brain-antioxidation potency, anticancer, antinociceptive, hepatoprotective, anti-diarrhealand wormicidal activities. ${ }^{[1]}$ Tribals of Kerala mainly in Wayanad, Malappuram, Palakkadu districts use this fruit extract because of its anticancerproperties. ${ }^{[7]}$ The important phytochemicals isolated from the plant are flavones, triterpenoids, cucurbitacin, 
phytosterols, saponins, sugars and phlobatannins ${ }^{[8]} 49-\mathrm{O}-\mathrm{b}-\mathrm{D}-$ glucopyranosyl rosmarinic acid and 4,49-O-di-b-Dglucopyranosyl rosmarinic acid. ${ }^{[3]}$

Botanically identified and authenticated fruits of Helicteres isora were procured from Siddha Medicinal Plant Garden, Mettur. The macroscopy of the samples was documented by Nikon COOLPIX5400 digital camera. Sectioning of the fresh samples were done to reveal the anatomy of the parts and the rest were dried, powdered, passed through mesh no.60, and preserved in an air-tight covers for powder microscopy. Transverse sections of the fruits were hand cut using a 7'o clock platinum blade stained with safranine and photographed using Nikon ECLIPSE E200 trinocular microscope attached with Nikon COOLPIX5400 digital camera under bright field light. Magnifications were indicated by the scale-bars. A pinch of the powdered fruits was mounted in glycerine after treating with $2 \% \mathrm{KOH}$ on a clean microscopic slide. Slides were observed under Nikon ECLIPSE E200 trinocular microscope and diagnostic characters were identified, photographed and documented. ${ }^{[9]}$

\section{Macroscopy}

The fruit of $H$. isora is greenish coloured when fresh turned to greenish brown when dried; cylindrical, pubescent with five follicles twisted spirally; 2 to $6 \mathrm{~cm}$ length and $2 \mathrm{~mm}$ to $1 \mathrm{~cm}$ diameter. The seeds are tuberculated (Figure 1); fruit is with characteristic odour and tastes slightly bitter.
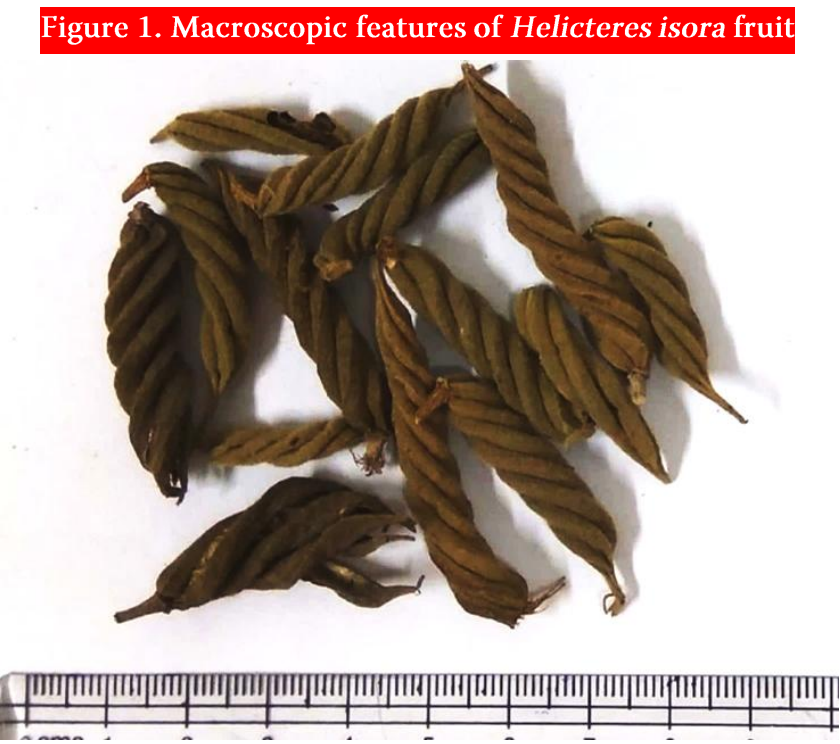

1.1 Dried Fruit

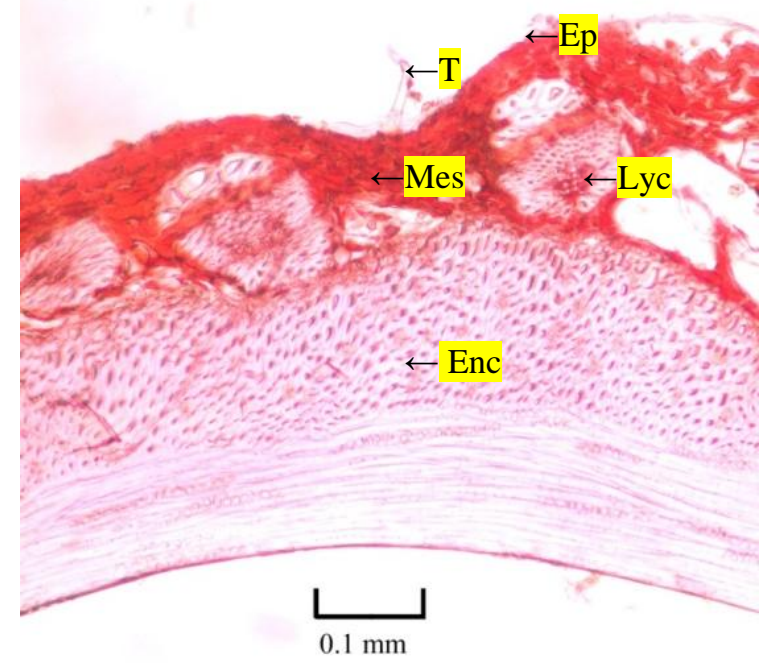

Fig2.1TS of Fruit 


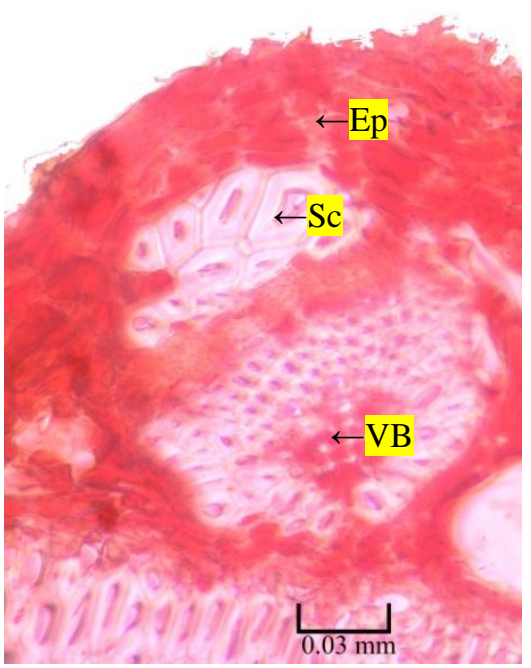

Fig 2.2 Outer region enlarged

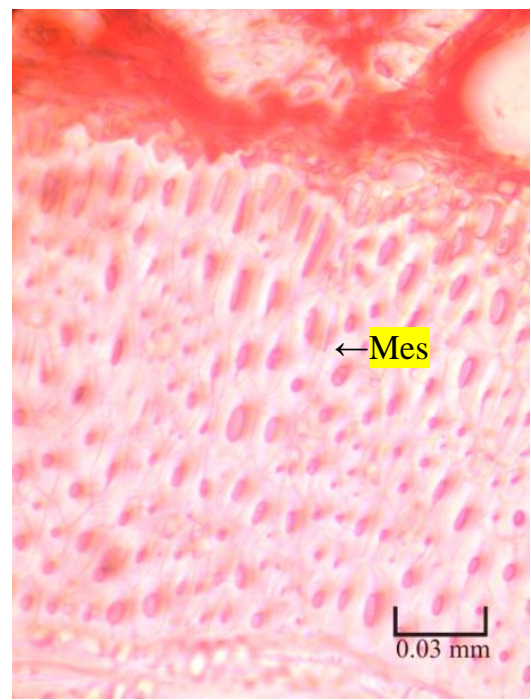

Fig 2.3 Middle portion enlarged

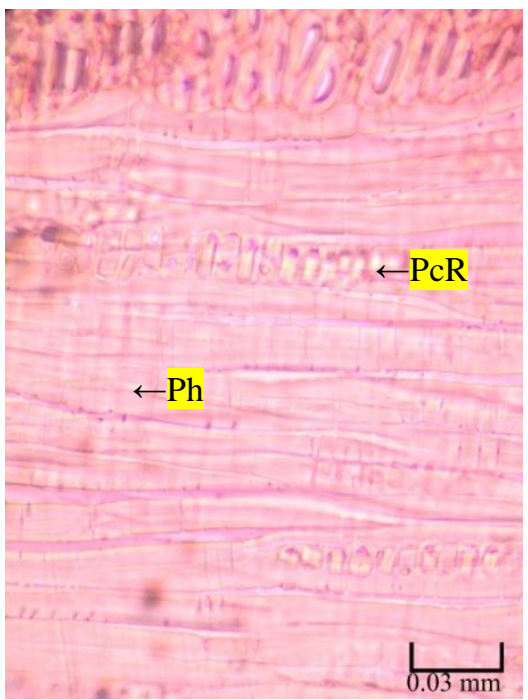

Fig 2.4 Inner region enlarged

Ep- epicarp; Enc - endocarp; Lyc- lysogenous cavity; Mes- mesocarp; PcR-prismatic crysals; Ph - phloem; Sc- stone cells; T- trichome; VB - vascular bundle.

\section{Microscopy}

TS of fruit shows pericarp which is clearly distinguished into outer epicarp, middle mesocarp and inner endocarpic regions. The pericarp shows a brown epicarp covered by number of stellate lignified trichomes along with stone cells and lysigenous mucilaginous cavities. The mesocarp is thick walled consisting of compactly arranged polygonal sclerenchymatous cells and vascular bundles and the endocarp is composed of fibres. The fibres are intermingled with prismatic crysals. The endosperm cells are thin walled lignified parenchyma cells which surrounds the cotyledonary region (Figure 2).

\section{Powder microscopy}

The powder is greenish brown coloured with characteristic odour and slightly bitter taste. Powder showed the characters like, cells of epicarp, stellate trichomes, fragment of mesocarp and endocarpic regions, endosperm cells, layers of testa, stone cells from pericarp, fibres and prismatic crystals (Figure 3).

H. isora is an important constituent drug in the Siddha formulation Valampuritailam. Hence the standardization of drug is necessary to confirm the purity and identity of the drug while preparing herbal formulations. The present study enlightens the macro-microscopic and powder characteristics of $H$. isora which will support the sample identification and determination of quality of the drug. Since the genus is characterized by twisted fruits, the identification of plant samples in dried drug form is very difficult and may affect the efficacy of the drug, if the actual parts are not used.

This study will be a useful record for the standardisation and authentication of ingredient drug, fruits of H. isora for the preparation of Valampuritailam.

Figure 3. Powder microscopy of Helicteres isora fruit

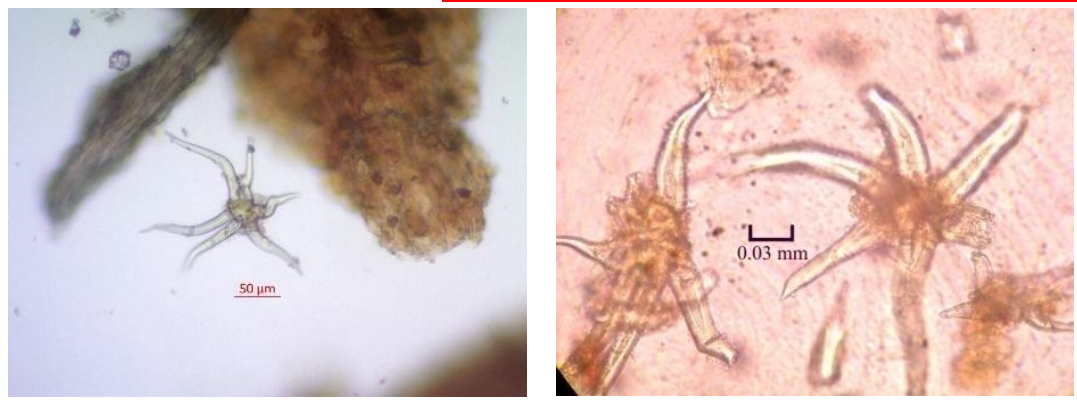

3.1 Stellate trichomes

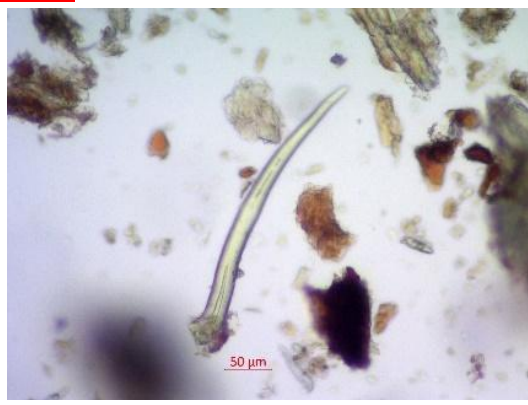

3.2 Arm of broken stellate trichome 

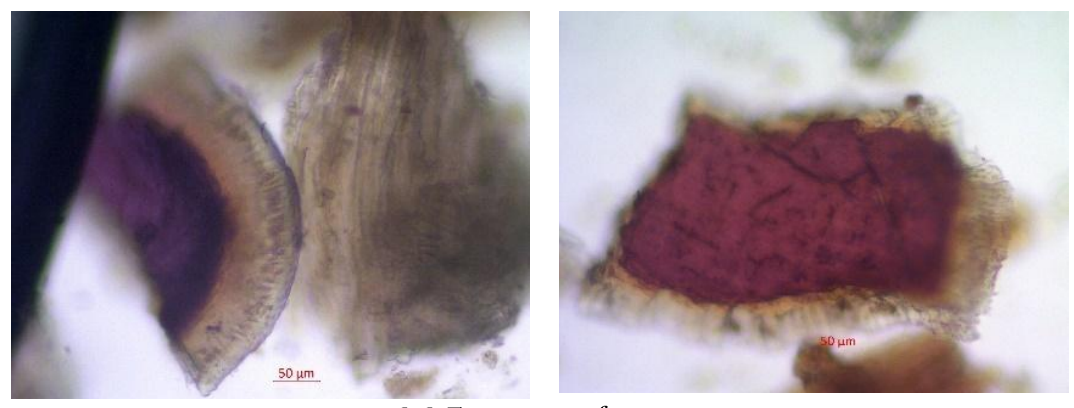

3.3 Fragment of testa

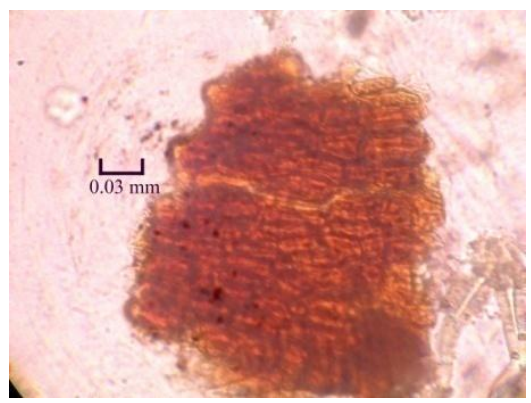

3.4 Epicarp
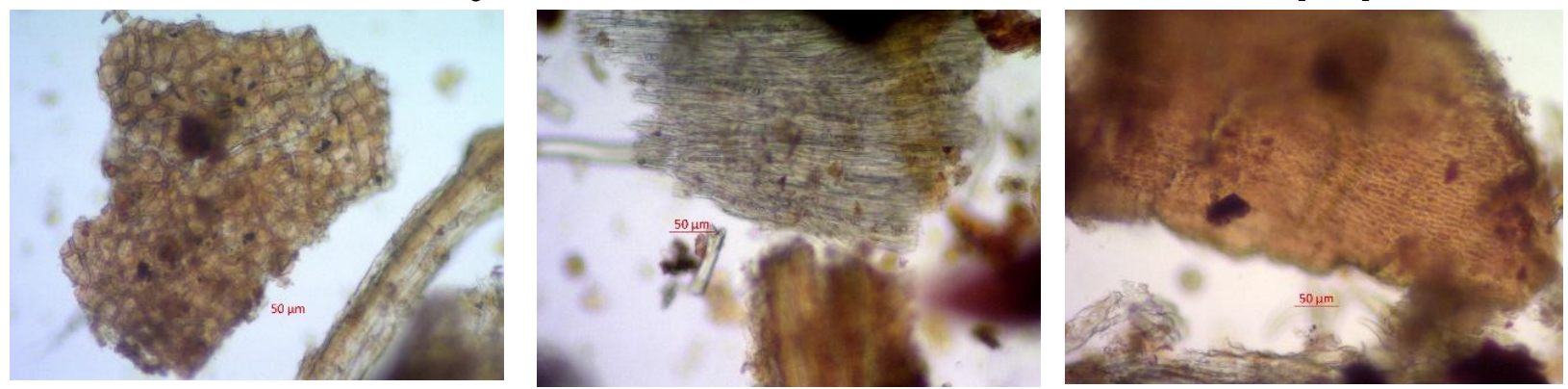

3.5 Mesocarp
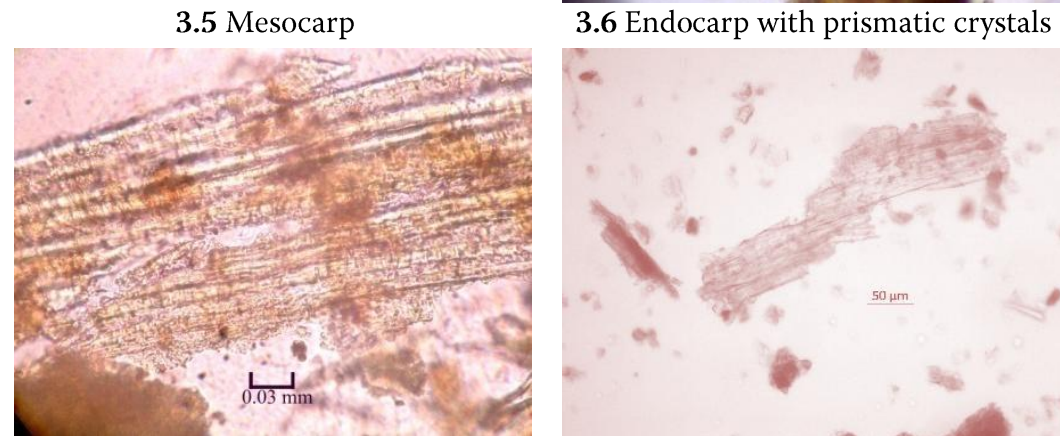

3.7 Lignified endosperm cells
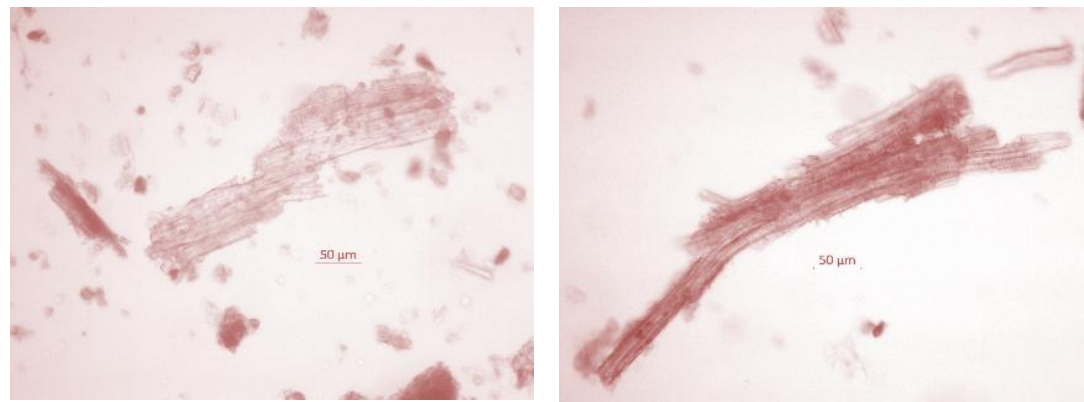

3.8 Fibres from mesocarp

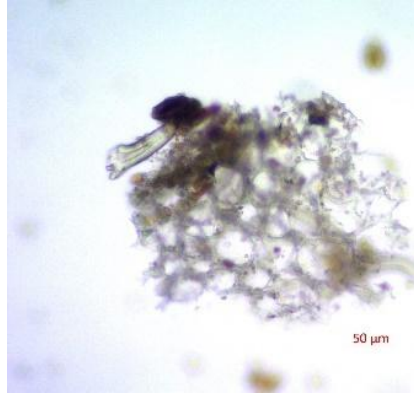

3.9 Parenchyma cells

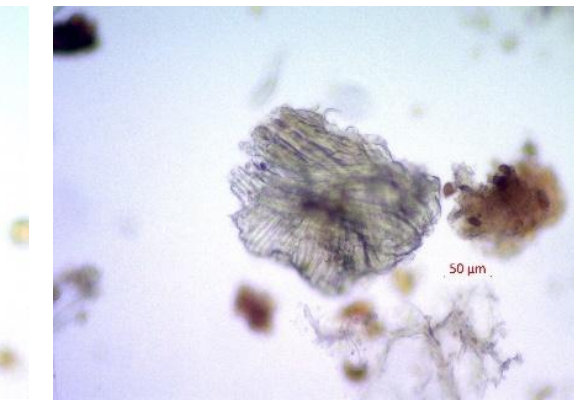

3.10 Criss-cross fibres

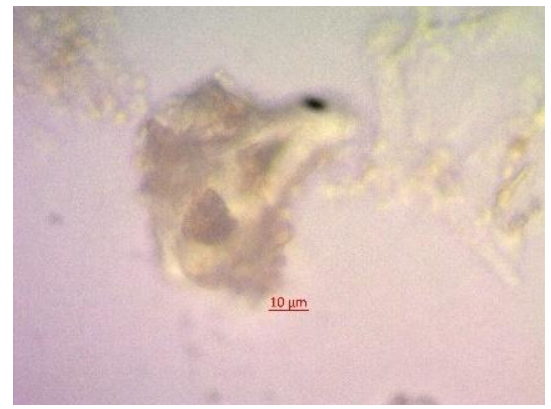

3.11 Stone cells from mesocarp

\section{CONFLICT OF INTEREST Nil}

\section{SOURCE OF SUPPORT Nil}

CONTRIBUTORS Mrs. Remya did the planning and conceptualization of the work, Mrs. Rubeena M contributed towards the design and data acquisition, Dr. Divya did the anatomical studies. Mrs. Brindha and Mrs. Erni carried out the morphological study and powder microscopic studies. Manuscript analysis and editing was carried out by Dr. KN Sunil Kumar.

\section{ACKNOWLEDGEMENT}

The authors extend their heartfelt thanks to Director General, CCRS, Chennai and Asst. Director In Charge, SCRI for immense support and Dr PadmaSubrahmaniam for providing fruit samples.

\section{REFERENCES}

1. Kumar N, Singh AK. Plant profile, phytochemistry and pharmacology of Avartani (Helicteresisora Linn.): A review. Asian Pacific journal of tropical biomedicine. 2014;4:S22-26.

2. Bhavamishra, Bhavaprakasha N, Chunekar KC, Pandey G, Chaukhambha Bharti Academy. 2010;279.

3. Girach RD, Aminuddin PA. Ehtenomedicinal uses of plants among the tribals of Singbhum district, Bihar, India. Ethenobotany. 1995;7:103-7. 
4. The siddha Formulary of India. Part I, The controller of publications, New Delhi, 2011;139

5. Girach RD. "Aminuddin. 1995 Ethnomedicinal uses of plants among the tribals of Singbhum District, Bihar, India. Ethnobotany 7. 103-107. En (Hi).;46.

6. Suthar M, Rathore GS, Pareek A. Antioxidant and antidiabetic activity of Helicteresisora (L.) fruits. Indian journal of pharmaceutical sciences. 2009 Nov;71(6):695.

7. Shah DV, ShyaleSomshekhar S, Soloman SS. Anthelmintic activity of HelicteresIsora Linn. fruits extract. World journal of pharmacy and pharmaceutical sciences. 2015;4(11)
8. Sabale PM, Grampurohit ND, Banerjee SK, Gaikwad DD, Gadhave MV. Recent advances on the phytochemical and pharmacological profile of plant Helicteresisora Linn. International research journal of pharmacy. 2012;3(4):14-7.

9. Mattummal R, Gopi DK, Sundaramoorthy B, Bobbili E, Andalil R, Sunil Kumar KN, Parameswaran SR. Morpho-anatomical evaluation of Punkam poo (Pongamiapinnata (L.) Pierre) a main ingredient of Siddha formulation PunkampooChoornnam. Journal of Ayueveda Medical Sciences. 2018;3(1):318-25. 